UDC 616.33-006.6

DOI: 10.21668/health.risk/2019.1.04.eng

\title{
RISK OF MORBIDITY WITH STOMACH CANCER AMONG WORKERS EMPLOYED AT RADIATION-HAZARDOUS ENTERPRISE
}

\author{
G.V. Zhuntova, E.S. Grigor'eva, T.V. Azizova
}

The Southern Urals Biophysics Institute of the RF Federal Medical and Biological Agency, 19 Ozerskoe drive, Ozersk, 456780, Russian Federation

We performed retrospective research among a cohort made up of workers employed at "Mayak" Production Association (Mayak PA), a state nuclear enterprise, who had been exposed to long-term external gamma-irradiation and internal alpha-irradiation caused by plutonium-239 under inhalation introduction. Our research goal was to assess impacts exerted by occupational irradiation and non-radiation factors on a risk of morbidity with stomach cancer (SC) in workers employed at Mayak PA.

We used individual data on occupational irradiation doses obtained from "Dosimetric system for Mayak PA workers - 2008" for external gamma-irradiation, and "Dosimetric system for Mayak PA workers - 2013" for internal alpha-irradiation. We applied Poisson regression to calculated odds ratio (OR) for morbidity with stomach cancer among the examined cohort both for radiation and non-radiation factors.

We detected statistically significant influence exerted on risk of morbidity with SC among workers employed at Mayak PA by the following factors: age, sex, attitudes towards to smoking and alcohol intake, stomach and duodenum ulcer, and external gamma-irradiation. Taking into account adjustments as per non-radiation factors, we detected a statistically significant increase in OR of morbidity with SC which was equal to 1.48 (95\% CI 1.10; 1.98), when a dose of external gamma-irradiation accumulated in the stomach walls was more than $1.0 \mathrm{~Gy}$. We didn't detect any correlation between risk of morbidity with CS among the examined cohort and internal alpha-irradiation.

Given that data obtained in epidemiologic research concerning impacts exerted by occupational irradiation on SC risks are ambiguous, it is necessary to clarify the obtained results and to perform more profound analysis of dose - response relationship among a more extended cohort of workers employed at Mayak PA.

Key words: morbidity risk, stomach cancer, gamma-irradiation, alpha-irradiation, smoking, alcohol, ulcer, dose - response relationship.

Stomach cancer is among the most widely spread malignant neoplasms though over the last decades there has been a slight decrease in morbidity and mortality caused by it in most countries all over the world, including Russia $[1,2]$. Stomach cancer is a polyetiologic disease that occurs due to complicated interaction between environmental factors, and impacts exerted by this interaction to a great extent depend on genetically determined peculiarities of a body [3].

Infection with Helicobacterpylori (H. pylori), nutrition, and alcohol intake are considered to be the basic risk factors that cause stomach cancer [4-6]. About $10 \%$ of stomach cancer cases among population are caused by inherited susceptibility to the disease [7]. Certain industrial agents (asbestos, chromium, nickel, coal, aromatic hydrocarbons, etc.) were shown to also contribute into stomach cancer etiology [8-11].

Influence exerted by ionizing irradiation on morbidity and mortality caused by stomach cancer was revealed in epidemiologic research performed among people living in Hiroshima and Nagasaki who had survived the atomic bombing as well as among patients who had undergone radiation therapy [12-19]. Workers employed at the nuclear enterprise Mayak PA

(C) Zhuntova G.V., Grigor'eva E.S., Azizova T.V., 2019

Galina V. Zhuntova - Candidate of Medical Sciences, Leading Researcher; Clinical Department (e-mail: clinic@subi.su; tel.: +7 (351) 302-95-41; ORCIDID: http://orcid.org/0000-0003-4407-3749).

Evgenia S. Grigor'eva - Researcher, Clinical Department (e-mail: clinic@subi.su; tel.: +7 (351) 302-93-73; ORCIDID: http://orcid.org/0000-0003-1806-9922).

Tamara V. Azizova - Candidate of Medical Sciences, Deputy Director responsible for Research, Head of the Clinical Department (e-mail: clinic@subi.su; tel.: +7 (351) 302-91-90; ORCIDID: http://orcid.org/0000-0001-6954-2674). 
and exposed to long-term irradiation turned out to run elevated risks of malignant neoplasms; however, data related to stomach cancer are rather ambiguous [20-22]. Up to now, a period of observations performed on Mayak PA workers has been extended considerably and there are new improved techniques for assessing doses of occupational internal alphairradiation [23] and it creates better conditions for refining previously obtained results on influence exerted by ionizing irradiation on stomach cancer risk.

Our research goal was to assess influence exerted by occupational irradiation and nonradiation factors on stomach cancer morbidity over 1948-2013 among workers employed at basic enterprises belonging to Mayak PA.

Data and methods. We performed our research among workers who were first employed by basic Mayak PA works (reactor, radiochemical, and plutonium one) in 1948-1982; the cohort included 22,377 people, $25 \%$ of them were women. The observation period started on a day when a worker was employed and lasted till December 31, 2013 (or until a day when stomach cancer was diagnosed or a day of death if it happened before this date) or till the last date on which medical information about a person was available (for those who moved somewhere and ceased to be observed). As on December 31, 2013, life status was detected for $95 \%$ of cohort members; $62 \%$ of them were dead. Average age $( \pm$ standard deviation) at the moment of death was equal to $61.5 \pm 13.6$ for men, and to $70.5 \pm 12.4$ for women; average age of those who were alive at the end of December 2013 amounted to $68.5 \pm 10.4$ for men; and to $76.6 \pm 9.8$, for women.

Personnel employed at all the basic works of Mayak PA were exposed to general external gamma-irradiation, and those who were employed at radiochemical and plutonium works were additionally exposed to alpha-active aerosols of plutonium-239. In our research we used estimations of occupational irradiation doses calculated on the basis of up-to-date dosimetric systems, "Dosimetric system for Mayak PA workers - 2008" for external gamma-irradiation doses and
"Dosimetric system for Mayak PA workers 2013" for doses of internal alpha-irradiation caused by incorporated plutonium [23, 24].

External irradiation has been monitored since PA Mayak started its operations and individual gamma-irradiation doses are known for each worker. Monitoring over internal irradiation has been introduced gradually since the late 1960ties; therefore, internal alpha-irradiation doses are detected for $31 \%$ workers exposed to plutonium-239 aerosol at their work places as the activity of this nuclide in their urine has been measured $[23,24]$. 55\% workers in the examined cohort were employed by Mayak PA in 1948-1958 when radiation exposure on personnel was the highest. Most workers (81\%) started their work at the enterprise when they were younger than 30 .

Data on diseases that workers had during the observation period were collected for 21,740 cohort members (97\%); attitudes to smoking (93\% workers) and its quantitative characteristics (71\% workers) were known for most of them, as well as attitudes towards alcohol intake ( $85 \%$ workers).

To perform an integral assessment of how long and intense smoking was, we applied smoking index (SI) calculated as per the following formula: SI = number of cigarettes packs smoked a day $\times$ duration of smoking (pack $\times$ years). Workers who consumed alcohol in rather large doses every day or had chronic alcoholism in their case history as per data obtained from addiction clinics were ranked as those who abused alcohol.

Besides, we examined influences exerted on morbidity with stomach cancer by the following diseases in the digestive system: stomach ulcer, duodenum ulcer, gastritis, duodenitis, malignant neoplasms in the stomach (codes K25-K26, K29, D13.1 of the ICD-10). All the above-mentioned diseases were taken into account only if they had been detected not later than 2 years prior to stomach cancer was diagnosed (to the end of the observation over the cohort); it was done in order to exclude an already existing but not diagnosed tumor process which can have similar symptoms at its early stages. 
Odds ratio (OR) for non-radiation factors was calculated on the basis of Poisson regression with corrections for attained age and sex. When calculating OR which was related to occupational irradiation, we took into account corrections for smoking status, alcohol intake, and occurrence of stomach and duodenum ulcer. Besides, when OR related to external gammairradiation was calculated, we made a correction for internal irradiation caused by incorporated plutonium; workers who weren't covered with monitoring over alpha-irradiation were attributed into a separate category. Analysis of stomach cancer risk caused by internal alphairradiation was performed only for workers who underwent procedures for control over plutonium contents in their bodies; the analysis was accomplished taking into account corrections for external gamma-irradiation doses.

All the calculations were made with AMFIT module of EPICURE software [25]. Discrepancies were considered to be statistically significant at $p<0.05$. External gammairradiation doses and internal alpha-irradiation doses absorbed in the stomach walls as well as smoking index were considered to be timedependent variables. Smoking status and smoking index value, as well as attitudes towards alcohol intake were taken at the moment when the observation over the cohort was over (or stomach cancer was diagnosed).

Results and discussion. Our research included 343 stomach cancer cases (280 men and 63 women) diagnosed in workers from the examined cohort during a period from the moment they had started working at basic Mayak PA plants to December 31, 2013. 248 workers $(72 \%)$ had the stomach cancer diagnosis confirmed by histology results; in all other cases it was confirmed by clinical data.

Workers who suffered from stomach cancer had average total external irradiation dose absorbed in the stomach wall $\pm \mathrm{SD}$ equal to $0.66 \pm 0.83$ Gy which was higher than among the examined cohort overall $(0.46 \pm 0.66 \mathrm{~Gy})$. Discrepancies in internal alpha-irradiation doses absorbed in the stomach walls which were equal to $0.0012 \pm 0.0026$ Gy in patients with stomach cancer and $0.0014 \pm 0.0064$ Gy in the cohort overall were not so significant. Distribution of stomach cancer cases and workers in the examined cohort depending on occupational irradiation doses is shown on Figures 1 and 2.

OR for stomach cancer morbidity was lower for women than for men and amounted to 0.35 (95\% CI 0.27; 0.46) (Table 1). Risk of stomach cancer in the examined cohort depended on an attained age. We revealed a statistically significant OR decrease among workers younger than 40 against those aged $40-45$ and growing OR in older age categories (after 50). Maximum OR value for stomach cancer morbidity in the examined cohort was detected for people older than 70 and was equal to $7.53(95 \%$ CI $4.84 ; 12.22$ ) (Table 1 ).

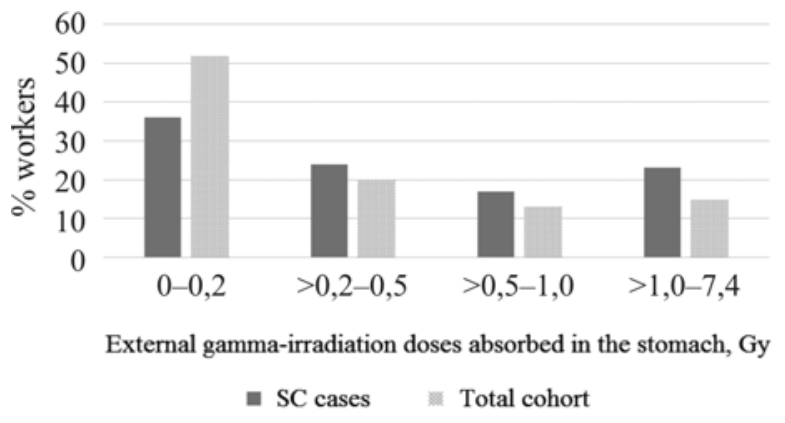

Figure 1. Distribution of workers in the examined cohort and stomach cancer cases depending on total external gamma-irradiation doses absorbed in the stomach walls

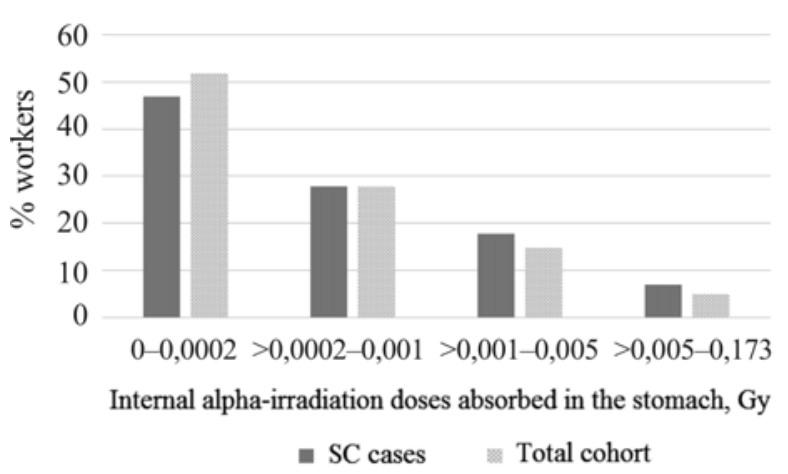

Figure 2. Distribution of workers in the examined cohort and stomach cancer cases depending on total internal alpha-irradiation doses absorbed in the stomach walls 
Table 1

Influence exerted by sex, age and a calendar period when a tumor was diagnosed on stomach cancer risk in the examined cohort

\begin{tabular}{|c|c|c|c|}
\hline Factor & Number of cases & Person-years of observation & OR $(95 \% \mathrm{CI})$ \\
\hline \multicolumn{4}{|l|}{ Sex: } \\
\hline men & 280 & 396,205 & 1 \\
\hline women & 63 & 168,459 & $0.35(0.27 ; 0.46)$ \\
\hline \multicolumn{4}{|c|}{ Age at which stomach cancer was diagnosed, years: } \\
\hline$<20$ & 0 & 9,616 & - \\
\hline$[20-25)$ & 0 & 44,885 & - \\
\hline$[25-30)$ & 5 & 59,589 & $0.22(0.07 ; 0.53)$ \\
\hline$[30-35)$ & 9 & 60,124 & $0.39(0.17 ; 0.82)$ \\
\hline$[35-40)$ & 11 & 61,104 & $0.48(0.23 ; 0.96)$ \\
\hline$[40-45)$ & 23 & 62,346 & 1 \\
\hline$[45-50)$ & 30 & 61,045 & $1.34(0.78 ; 2.34)$ \\
\hline$[50-55)$ & 41 & 55,271 & $2.06(1.25 ; 3.48)$ \\
\hline$[55-60)$ & 48 & 46,315 & $2.94(1.81 ; 4.91)$ \\
\hline$[60-65)$ & 53 & 37,395 & $4.12(2.56 ; 6.85)$ \\
\hline$[65-70)$ & 36 & 28,758 & $3.77(2.25 ; 6.45)$ \\
\hline$[70+$ & 87 & 38,216 & $7.53(4.84 ; 12.22)$ \\
\hline \multicolumn{4}{|c|}{ A calendar period during which stomach cancer was diagnosed: } \\
\hline $1948-1950$ & 0 & 7,623 & - \\
\hline $1951-1955$ & 7 & 31,331 & $1.77(0.71 ; 3.78)$ \\
\hline $1956-1960$ & 9 & 38,722 & $1.46(0.66 ; 2.91)$ \\
\hline $1961-1965$ & 9 & 47,408 & $0.91(0.41 ; 1.80)$ \\
\hline $1966-1970$ & 20 & 48,183 & $1.34(0.76 ; 2.26)$ \\
\hline $1971-1975$ & 25 & 50,294 & $1.15(0.69 ; 1.87)$ \\
\hline $1976-1980$ & 28 & 56,778 & $0.89(0.55 ; 1.42)$ \\
\hline $1981-1985$ & 43 & 59,105 & 1 \\
\hline $1986-1990$ & 30 & 55,262 & $0.54(0.34 ; 0.86)$ \\
\hline $1991-1995$ & 34 & 50,110 & $0.51(0.32 ; 0.80)$ \\
\hline $1996-2000$ & 47 & 43,925 & $0.62(0.41 ; 0.96)$ \\
\hline $2001-2005$ & 35 & 37,201 & $0.44(0.27 ; 0.69)$ \\
\hline $2006-2010$ & 34 & 28,785 & $0.44(0.27 ; 0.70)$ \\
\hline $2011-2013$ & 22 & 9,937 & $0.66(0.38 ; 1.12)$ \\
\hline
\end{tabular}

The obtained results are well in line with population data according to which stomach cancer is diagnosed 1.5-2.5 times more frequently in men than in women; experts think it can be due to different attitudes towards smoking, different nutrition, and different frequency of contacts with hazardous industrial factors [26]. It is also known that morbidity with stomach cancer taken for the overall population grows with age, especially among people older than 50, and reaches its peak among people aged 70-75 [2, 26].

We observed a statistically significant decrease in OR for stomach cancer morbidity in the examined cohort in 1986-2010 against 1981-1985 (Table 1). Morbidity with stomach cancer has decreased over last decades both in Russia and many other countries all over the world; in experts' opinion, it is due to changes in nutrition structure, lower frequency of infection with $H$. pylori, and lower prevalence of other risk factors that can cause stomach cancer, including improved working conditions $[1,2]$.

OR for stomach cancer morbidity was statistically significantly higher for smoking workers in the examined cohort and was equal to $1.57(95 \%$ CI $1.17 ; 2.13)$ as compared to 
those who didn't smoke (Table 2). A statistically significant increase in OR which was equal to $1.40(95 \%$ CI $1.03 ; 1.91)$ was also detected for smokers with SI greater than 20 pack $\times$ years. Besides, stomach cancer risk was statistically significantly higher for men who abused alcohol: OR $=2.00$ (95\% CI 1.22; 3.49) (Table 2).

Smoking is a well-known and well-proven risk factor that causes stomach cancer; according to meta-analysis data, it causes 1.5-1.6 times higher risk of the disease [27]. Alcohol abuse also contributes into stomach cancer etiology and it was revealed by meta-analysis and in large cohort research. There are data that intake of strong spirits in a dose higher than $60 \mathrm{~g}$ /day in terms of ethanol leads to 1.64 times higher stomach cancer risk [28]. Smoking, al- cohol intake and H.pylori infection were shown to interact in a synergic manner causing greater inflammation and elevated probability of malignant transformations in the stomach mucous tunic [29].

Russia is among countries where there is high prevalence of $H$. pylori, as $78.5 \%$ population in the country is infected with it [30]. However we, within our retrospective research, could only indirectly take into account the role played by this factor in stomach cancer etiology among workers employed at Mayak PA.

Clinical effects produced by $H$. pylori depend on localization and peculiarities of inflammation processes in the stomach [31]. H. pylori-associated atrophic gastritis and stomach ulcer are known to cause elevated stomach cancer risks [26, 31]. But at the same

Table 2

Influence exerted by smoking, alcohol intake, and chronic diseases on stomach cancer risk in the examined cohort

\begin{tabular}{|c|c|c|c|}
\hline Factor & $\begin{array}{l}\text { Number } \\
\text { of cases }\end{array}$ & $\begin{array}{l}\text { Person-years of the } \\
\text { observation }\end{array}$ & OR $(95 \% \mathrm{CI})$ \\
\hline \multicolumn{4}{|l|}{ Smoking, status: } \\
\hline never smoked & 111 & 241,531 & 1 \\
\hline gave up smoking & 67 & 112,659 & $0.77(0.54 ; 1.10)$ \\
\hline smoked & 159 & 201,964 & $1.57(1.17 ; 2.13)$ \\
\hline \multicolumn{4}{|l|}{ Smoking index, pack $\times$ years } \\
\hline never smoked & 111 & 241,531 & 1 \\
\hline$\leq 10$ & 15 & 76,748 & $0.60(0.33 ; 1.04)$ \\
\hline $10-20$ & 33 & 68,234 & $1.03(0.66 ; 1.57)$ \\
\hline$>20$ & 143 & 109,704 & $1.40(1.03 ; 1.91)$ \\
\hline \multicolumn{4}{|l|}{ Alcohol intake, status (men only): } \\
\hline didn't drink or did it rarely & 17 & 48,956 & 1 \\
\hline moderate drinkers & 146 & 242,713 & $1.36(0.85 ; 2.33)$ \\
\hline abused alcohol & 87 & 70,133 & $2.00(1.22 ; 3.49)$ \\
\hline \multicolumn{4}{|l|}{ Stomach ulcer: } \\
\hline no & 312 & 548,891 & 1 \\
\hline yes & 31 & 15,773 & $1.69(1.14 ; 2.42)$ \\
\hline \multicolumn{4}{|l|}{ Duodenum ulcer: } \\
\hline no & 326 & 535,042 & 1 \\
\hline yes & 17 & 29,623 & $0.49(0.29 ; 0.78)$ \\
\hline \multicolumn{4}{|l|}{ Gastritis and duodenitis: } \\
\hline no & 149 & 356,573 & 1 \\
\hline yes & 194 & 208,091 & $1.23(0.98 ; 1.54)$ \\
\hline \multicolumn{4}{|l|}{ Stomach polyps: } \\
\hline no & 338 & 561,803 & 1 \\
\hline yes & 5 & 2,861 & $1.18(0.42 ; 2.58)$ \\
\hline
\end{tabular}


time, when a patient suffers from duodenum ulcer or chronic gastritis with the increased secretory function, he or she runs lower stomach cancer risks $[26,31]$.

We detected a statistically significant increase in stomach cancer risk which was equal to $1.69(95 \%$ CI $1.14 ; 2.42)$ in the examined cohort for workers who suffered from stomach ulcer against those who didn't have this disease (Table 2). But in case a worker had duodenum ulcer, he or she, on the contrary, ran lower stomach cancer risk with OR $=0.49(95 \%$ CI $0.29 ; 0.78)$. We revealed a slight increase in OR for workers who suffered from gastritis and duodenitis and its estimation was close to the statistical significance boundary $(p<0.1)$. We didn't reveal any statistically significant correlation between stomach polyposis and stomach cancer among workers from the examined cohort but there were few cases of this disease (Table 2).

The performed analysis revealed a statistically significant increase in OR for stomach cancer morbidity when external gamma-irradiation doses absorbed in the stomach walls were higher than 1.0 Gy against those workers who had external irradiation doses not higher than 0.2 Gy (Table 3). Estimation of OR for stomach cancer morbidity calculated with corrections for sex, age, and alpha-irradiation, amounted to 1.37 (95\% CI 1.02; 1.83). We introduced additional corrections for smoking status, attitudes towards alcohol, and occurrence of stomach and duodenum ulcer, and OR estimation went up slightly to $1.48(95 \%$ CI 1.10 ; 1.98) (Table 3).

Table 3

Influence exerted by long-term total external gamma-irradiation on stomach cancer risk in the examined cohort

\begin{tabular}{|c|c|c|c|}
\hline $\begin{array}{l}\text { External gamma-irradiation dose } \\
\text { absorbed in the stomach walls, Gy }\end{array}$ & $\begin{array}{l}\text { Number } \\
\text { of cases }\end{array}$ & $\begin{array}{l}\text { Person-years } \\
\text { of the observation }\end{array}$ & OR $(95 \% \mathrm{CI})$ \\
\hline \multicolumn{4}{|c|}{ Model with corrections for sex, age, and alpha-irradiation: } \\
\hline$[0.0-0.2)$ & 123 & 284,928 & 1 \\
\hline$[0.2-0.5)$ & 83 & 107,64 & $1.26(0.95 ; 1.66)$ \\
\hline$[0.5-1.0)$ & 58 & 71,608 & $1.24(0.89 ; 1.69)$ \\
\hline$[1.0+$ & 79 & 82,125 & $1.37(1.02 ; 1.83)$ \\
\hline \multicolumn{4}{|c|}{ Model with corrections for sex, age, smoking status, and alpha-irradiation: } \\
\hline$[0.0-0.2)$ & 123 & 284,928 & 1 \\
\hline$[0.2-0.5)$ & 83 & 107,464 & $1.27(0.96 ; 1.68)$ \\
\hline$[0.5-1.0)$ & 58 & 71,608 & $1.26(0.91 ; 1.72)$ \\
\hline$[1.0+$ & 79 & 82,125 & $1.44(1.07 ; 1.93)$ \\
\hline \multicolumn{4}{|c|}{ Model with corrections for sex, age, smoking status, alcohol intake, and alpha-irradiation: } \\
\hline$[0.0-0.2)$ & 123 & 284,928 & 1 \\
\hline$[0.2-0.5)$ & 83 & 107,464 & $1.29(0.97 ; 1.70)$ \\
\hline$[0.5-1.0)$ & 58 & 71,608 & $1.29(0.93 ; 1.76)$ \\
\hline$[1.0+$ & 79 & 82,125 & $1.47(1.09 ; 1.97)$ \\
\hline \multicolumn{4}{|c|}{ Model with corrections for sex, age, smoking status, alcohol intake, stomach ulcer, and alpha-irradiation } \\
\hline$[0.0-0.2)$ & 123 & 284,928 & 1 \\
\hline$[0.2-0.5)$ & 83 & 107,464 & $1.28(0.96 ; 1.70)$ \\
\hline$[0.5-1.0)$ & 58 & 71,608 & $1.28(0.93 ; 1.75)$ \\
\hline$[1.0+$ & 79 & 82,125 & $1.47(1.09 ; 1.96)$ \\
\hline \multicolumn{4}{|c|}{$\begin{array}{l}\text { Model with corrections for sex, age, smoking status, alcohol intake, stomach ulcer, duodenum ulcer, } \\
\text { and alpha-irradiation: }\end{array}$} \\
\hline$[0.0-0.2)$ & 123 & 284,928 & 1 \\
\hline$[0.2-0.5)$ & 83 & 107,464 & $1.29(0.97 ; 1.71)$ \\
\hline$[0.5-1.0)$ & 58 & 71,608 & $1.29(0.93 ; 1.76)$ \\
\hline$[1.0+$ & 79 & 82,125 & $1.48(1.10 ; 1.98)$ \\
\hline
\end{tabular}


Table 4

Influence exerted by long-term total internal alpha-irradiation on stomach cancer risk in the examined cohort

\begin{tabular}{|c|c|c|c|}
\hline $\begin{array}{l}\text { Internal alpha-irradiation dose absorbed } \\
\text { in the stomach walls, Gy }\end{array}$ & $\begin{array}{c}\text { Number of } \\
\text { cases }\end{array}$ & $\begin{array}{l}\text { Person-years of the } \\
\text { observation }\end{array}$ & OR $(95 \% \mathrm{CI})$ \\
\hline \multicolumn{4}{|c|}{ Model with corrections for sex, age, and gamma-irradiation: } \\
\hline$[0.0-0.2)$ & 101 & 219,531 & 1 \\
\hline$[0.2-0.5)$ & 57 & 64,106 & $0.95(0.66 ; 1.35)$ \\
\hline$[0.5-1.0)$ & 35 & 27,361 & $1.04(0.66 ; 1.61)$ \\
\hline$[1.0+$ & 10 & 6,727 & $1.26(0.59 ; 2.42)$ \\
\hline \multicolumn{4}{|c|}{ Model with corrections for sex, age, smoking status, and gamma-irradiation: } \\
\hline$[0.0-0.2)$ & 101 & 219,531 & 1 \\
\hline$[0.2-0.5)$ & 57 & 64,106 & $0.93(0.65 ; 1.32)$ \\
\hline$[0.5-1.0)$ & 35 & 27,361 & $1.03(0.65 ; 1.60)$ \\
\hline$[1.0+$ & 10 & 6,727 & $1.26(0.59 ; 2.42)$ \\
\hline \multicolumn{4}{|c|}{ Model with corrections for sex, age, smoking status, alcohol intake, and gamma-irradiation: } \\
\hline$[0.0-0.2)$ & 101 & 219,531 & 1 \\
\hline$[0.2-0.5)$ & 57 & 64,106 & $0.93(0.65 ; 1.32)$ \\
\hline$[0.5-1.0)$ & 35 & 27,361 & $1.03(0.65 ; 1.60)$ \\
\hline$[1.0+$ & 10 & 6,727 & $1.24(0.58 ; 2.39)$ \\
\hline \multicolumn{4}{|c|}{ Model with corrections for sex, age, smoking status, alcohol intake, stomach ulcer, and gamma-irradiation } \\
\hline$[0.0-0.2)$ & 101 & 219,531 & 1 \\
\hline$[0.2-0.5)$ & 57 & 64,106 & $0.93(0.65 ; 1.31)$ \\
\hline$[0.5-1.0)$ & 35 & 27,361 & $1.03(0.65 ; 1.60)$ \\
\hline$[1.0+$ & 10 & 6,727 & $1.24(0.58 ; 2.41)$ \\
\hline \multicolumn{4}{|c|}{$\begin{array}{l}\text { Model with corrections for sex, age, smoking status, alcohol intake, stomach ulcer, duodenum ulcer, } \\
\text { and gamma-irradiation: }\end{array}$} \\
\hline$[0.0-0.2)$ & 101 & 219,531 & 1 \\
\hline$[0.2-0.5)$ & 57 & 64,106 & $0.92(0.64 ; 1.31)$ \\
\hline$[0.5-1.0)$ & 35 & 27,361 & $1.02(0.65 ; 1.59)$ \\
\hline$[1.0+$ & 10 & 6,727 & $1.20(0.56 ; 2.31)$ \\
\hline
\end{tabular}

We didn't detect any influence exerted by internal alpha-irradiation on stomach cancer risk in the examined cohort (Table 4) and the result is well in line with the previously obtained ones [20-22]. Other researchers also didn't reveal any carcinogenic effects in the stomach when alpha-irradiators ( $\mathrm{Ra}, \mathrm{Th}, \mathrm{Rn}$, $\mathrm{Pu})$ were introduced in a body; it is most frequently explained by rather insignificant doses of such irradiation absorbed in this organ [32-34].

Previously experts who had conducted "case - control" research on workers employed at Mayak PA revealed an elevated stomach cancer risk when total external gammairradiation doses were higher than 3.0 Gy [20]. Cohort research performed on workers employed at basic Mayak PA plants revealed increased risks of morbidity (observation period 1948-2004) [21] and mortality (observation period 1948-2008) caused by stomach cancer when external gamma-irradiation doses grew [22]; however, estimations of excessive relative risks were only close to the statistical significance boundary $(\mathrm{p}<0.07$ and $<0.06$ accordingly).

We prolonged the observation period up to 2013 within the framework of our research; also, when assessing influence exerted by occupational irradiation on stomach cancer risk, we took into account a wider range of non-radiation factors including chronic stomach diseases that can be caused by infection with $H$. pylori.

Research performed on people who had survived the atomic bombing in Japan revealed a dependence between a dose of acute gamma- 
neutron irradiation and risks of morbidity and mortality caused by stomach cancer $[12,13]$. Elevated stomach cancer risks were also detected for patients who had undergone radiation therapy or had had ${ }^{131}$ I introduced into their bodies when hyperthyrosis had been treated $[14-19,35]$.

But a lot of researchers who examined personnel employed at nuclear enterprises in foreign countries, people living on territories contaminated with radiation emissions and in zones where natural radiation background was a bit increased didn't obtain any convincing evidence that there was a correlation between long-term irradiation in small doses and stomach cancer risk [36-39]. However, an elevated stomach cancer risk caused by exposure to radiation was revealed for a combined cohort of workers employed at nuclear enterprises in France, Great Britain, and the USA, when average external gamma-irradiation doses absorbed in the stomach were equal to $20 \mathrm{mGy}$ [40].

Conclusion. The research performed on workers employed at Mayak PA revealed an elevated stomach cancer risk under long-term external gamma-irradiation in total doses ab- sorbed in the stomach walls equal to more than 1.0 Gy. Given the fact that data on influence exerted by occupational irradiation on stomach cancer risks that have been accumulated so far are rather ambiguous, it is necessary to analyze a dose-effect relationship in greater detail and on an extended cohort of workers employed at Mayak PA.

We didn't reveal any influence exerted by long-term internal alpha-irradiation on stomach cancer morbidity in workers employed at Mayak PA.

Stomach cancer risk for the examined cohort, just as for overall population, depended on an attained age, sex, attitudes towards smoking and alcohol intake, as well as on occurrence of stomach and duodenum ulcer.

Funding sources. The present research has been accomplished within the frameworks of the Agreement No. 501-1-18 "Effects produced by chronic irradiation" signed on July 23, 2018 with the Urals Scientific and Practical Center for Radiation Medicine of the Federal Biomedical Agency

Conflict of interests. The authors state there is no any conflict of interests.

\section{References}

1. Balakrishnan M., George R., Sharma A., Graham D.Y. Changing Trends in Stomach Cancer Throughout the World. Current Gastroenterology Reports, 2017, vol. 19, no. 8, 36 p. DOI: $10.1007 / \mathrm{s} 11894-017-0575-8$

2. Zlokachestvennye novoobrazovaniya v Rossii v 2013 godu (zabolevaemost' i smertnost') [Malignantneoplasms in Russian 2013 (morbidity and mortality)]. In: A.D. Kaprin, V.V. Starinskii, G.V. Petrova eds. Moscow, MNIOI im. P.A. Gertsena Publ., 2015, 250 p. (in Russian).

3. Shi J., Qu Y-P., Hou P. Pathogenetic mechanisms in gastric cancer. World Journal of Gastroenterology, 2014, vol. 20, no. 38, pp. 13804-13819. DOI: 10.3748/wjg.v20.i38.13804

4. Eusebi L.H., Zagari R.M., Bazzoli F. Epidemiology of Helicobacter pylori infection. Helicobacter, 2014, no. 19, suppl. 1, pp. 1-5. DOI: 10.1111/hel.12165

5. Agudo A., Cayssials V., Bonet C. [et al.]. Inflammatory potential of the diet and risk of gastric cancer in the European Prospective Investigation into Cancer and Nutrition (EPIC) study. The American Journal of Clinical Nutrition, 2018, vol. 107, no. 4, pp. 607-616.

6. Sinha D.N., Suliankatchi R.A., Gupta P.C, [et al.]. Global burden of all-cause and cause-specific mortality due to smokeless tobacco use: systematic review and meta-analysis. Tobacco Control, 2018, vol. 27, no. 1, pp. 35-42. DOI: 10.1136/tobaccocontrol-2016-053302

7. McLean M.H., El-Omar E.M. Genetics of gastric cancer. Nature Reviews Gastroenterology \& Hepatology, 2014, no. 11, pp. 664-674. DOI: 10.1038/nrgastro.2014.143

8. Saghier A.A., Kabanja J.H., Afreen S., Sagar M. Gastric cancer: Environmental risk factors, treatment and prevention. Journal of Carcinogenesis and Mutagenesis, 2013, № S14:008. DOI: 10.4172/2157-2518

9. Welling R., Beaumont J.J., Petersen S.J. [et al.]. Chromium VI and stomach cancer: a metaanalysis of the current epidemiological evidence. Occupational and Environmental Medicine, 2015, vol. 72, no. 2, pp. 151-159. DOI: 10.1136/oemed-2014-102178 
10. Boniol M., Koechlin A., Boyle P. Meta-analysis of occupational exposures in the rubber manufacturing industry and risk of cancer. International Journal of Epidemiology, 2017, vol. 46, no. 6, pp. 1940-1947. DOI: 10.1093/ije/dyx146

11. Di Ciaula A. Asbestos ingestion and gastrointestinal cancer: a possible underestimated hazard. Expert Review of Gastroenterology \& Hepatology, 2017, vol. 11, no. 5, pp. 419-425. DOI: 10.1080/17474124.2017

12. Preston D.L., Ron E., Tokuoka S. [et al.]. Solid Cancer Incidence in Atomic Bomb Survivors: 1958-1998. Radiation Research, 2007, vol. 168, no. 1, pp. 1-64.

13. Ozasa K., Shimizu Y., Suyama A. [et al.]. Studies of the mortality of atomic bomb survivors, Report 14, 1950-2003: an overview of cancer and non-cancer diseases. Radiation Research, 2012, vol. 177 , no. 3 , pp. $229-243$.

14. Gilbert E.S., Curtis R.E., Hauptmann M. [et al.]. Stomach Cancer Following Hodgkin Lymphoma, Testicular Cancer and Cervical Cancer: A Pooled Analysis of Three International Studies with a Focus on Radiation Effects. Radiation Research, 2017, no. 187, pp. 186-195.

15. Morton L.M., Dores G.M., Curtis R.E. [et al.]. Stomach cancer risk after treatment for Hodgkin lymphoma. Journal of Clinical Oncology, 2013, no. 31, pp. 3369-3377.

16. Hauptmann M., Fossa S.D., Stovall M., von Leeuwen F.E. [et al.]. Increased stomach cancer risk following radiotherapy for testicular cancer. British Journal of Cancer, 2015, no. 112, pp. 44-51.

17. Kleinerman R.A., Smith S.A., Holowaty E. [et al.]. Radiation dose and subsequent risk for stomach cancer in long-term survivors of cervical cancer. International Journal of Radiation Oncology, Biology, Physics, 2013, no. 86, pp. 922-929.

18. Little M.P., Stovall M., Smith S.A., Kleinerman R.A., A reanalysis of curvature in the dose response for cancer and modifications by age at exposure following radiotherapy for benign disease. International Journal of Radiation Oncology, Biology, Physics, 2013, vol. 85, no. 2, pp. 451-459. DOI: 10.1016/j.ijrobp.2012.04.029

19. Carr Z.A., Kleinerman R.A., Stovall M. [et al.]. Malignant neoplasms after radiation therapy for peptic ulcer. Radiation Research, 2002, vol. 157, no. 6, pp. 668-677.

20. Zhuntova G.V., Tokarskaya Z.B., Belyaeva Z.D. Vliyanie radiatsionnykh i neradiatsionnykh faktorov riska na zabolevaemost' rakom zheludka u rabotnikov PO «Mayak» [Influence of Radiation and Non-radiation Factors in Stomach Cancer Incidence among Mayak PA Workers]. Meditsinskaya radiologiya i radiatsionnaya bezopasnost', 2009, vol. 54, no. 2, pp. 38-46 (in Russian).

21. Hunter N., Kuznetsova I.S., Labutina E.V., Harrison J.D. Solid cancer incidence other than lung, liver and bone in Mayak workers: 1948-2004. British Journal of Cancer, 2013, vol. 109, no. 7, pp. 1989-1996.

22. Sokolnikov M., Preston D., Gilbert E. [et al.]. Radiation Effects on Mortality from Solid Cancers Other than Lung, Liver, and Bone Cancer in the Mayak Worker Cohort: 1948-2008. PLOS ONE, 2015, vol. 10, no. 2, p. e0117784.

23. Birchall A., Vostrotin V., Puncher M. [et al.]. The Mayak Worker Dosimetry System (MWDS-2013) for internally deposited plutonium: an overview. Radiation Protection Dosimetry, 2017, no. 176, pp. 10-31.

24. Vasilenko E.K., Khokhryakov V.F., Miller S.C. [et al.]. Mayak worker dosimetry study: an overview. Health Physics, 2007, vol. 93, no. 3, pp. 190-206.

25. Preston D.L., Lubin J.H., Pierce D.A., McConney M.E. Epicure Users Guide. Seattle, Washington: Hirosoft International Corporation Publ., 1993.

26. Guggenheim D.E., Shah M.A. Gastric cancer epidemiology and risk factors. Journal of Surgical Oncology, 2013, no. 107, pp. 230-236.

27. Ladeiras-Lopes R., Pereira A.K., Ngueira A. [et al.]. Smoking and gastric cancer: systematic review and meta-analysis of cohort studies. Cancer Causes and Control, 2008, no. 19, pp. 689-701.

28. Duell E.J., Travier N., Lujan-Barroso L. [et al.]. Alcohol consumption and gastric cancer risk in the European Prospective Investigation into Cancer and Nutrition (EPIC) cohort. The American Journal of Clinical Nutrition, 2011, no. 94, pp. 1266-1275.

29. Salaspuro M. Interrelationship between alcohol, smoking, acetaldehyde and cancer. Novartis Foundation symposium, 2007, no. 285, pp. 80-89.

30. Hooi J.K.Y., Lai W.Y., Ng W.K., Global Prevalence of Helicobacter pylori Infection: Systematic Review and Meta-Analysis. Gastroenterology, 2017, no. 153, pp. 420-429. DOI: 10.1053/j.gastro.2017.04.022 
31. White J.R., Winter J.A., Robinson K. Differential inflammatory response to Helicobacter pylori infection: etiology and clinical outcomes. Journal of Inflammation Research, 2015, no. 8, pp. 137-147.

32. Mori T., Kato Y., Hatakeyama S. [et al.]. Results of the first series of follow-up studies on Japanese Thorotrast patients and their relationships to an autopsy series. Radiation Research, 1999, vol. 152, no. 6 , pp. $72-80$.

33. Nekolla E.A., Kellerer A.M., Kuse-Isingschulte M. [et al.]. Malignancies in patients treated with high doses of Radium-224. Radiation Research, 1999, vol. 152, no. 6, pp. 3-7.

34. Omar R.Z., Barber J.A., Smith P.G. Cancer morbidity among plutonium workers at the Sellafield plant of British Nuclear Fuels. British Journal of Cancer, 1999, vol. 79, no. 7/8, pp. 1288-1301.

35. Holm L.E., Hall P., Wiklund K. [et al.]. Cancer risk after iodine-131 therapy for hyperthyroidism. Journal of the National Cancer Institute, 1991, vol. 83, no. 15, pp. 1072-1077.

36. Cardis E., Vrijheid M., Blettner M. [et al.]. The 15-Country Collaborative Study of Cancer Risk among Radiation Workers in the Nuclear Industry: estimates of radiation-related cancer risks. Radiation Research, 2007, vol. 167, no. 4, pp. 396-416.

37. Boice J.D. Jr., Sarah S., Cohen M.T. [et al.]. Updated Mortality Analysis of Radiation Workers at Rocketdyne (Atomics International), 1948-2008. Radiation Research, 2011, no. 176, pp. 244-258.

38. Metz-Flamant C., Samson E., Cae"r-Lorho S. [et al.]. Solid Cancer Mortality Associated with Chronic External Radiation Exposure at the French Atomic Energy Commission and Nuclear Fuel Company. Radiation Research, 2011, no. 176, pp. 115-127.

39. Tao Z., Cha Y., Sun Q. Cancer mortality in high background radiation area of Yangiiang, China, 1979-1995. Zhonghua Yi XueZaZhi, 1999, vol. 79, no. 7, pp. 487-492.

40. Richardsona D.B., Cardisb E., Danielse R.D. [et al.]. Site-specific Solid Cancer Mortality After Exposure to Ionizing Radiation: A Cohort Study of Workers (INWORKS). Epidemiology, 2018, vol. 29, no. 1, pp. 31-40. DOI: 10.1097/EDE.0000000000000761

Zhuntova G.V., Grigor'eva E.S., Azizova T.V. Risk of morbidity with stomach cancer among workers employed at radiation-hazardous enterprise. Health Risk Analysis, 2019, no. 1, pp. 40-49. DOI: 10.21668/health.risk/2019.1.04.eng

Received: 29.10 .2018

Accepted: 19.01.2019

Published: 30.03 .2019 